\title{
UTILIZAÇÃO DE PERICÁRDIO BOVINO CONSERVADO EM GLICERINA 98\% NA HERNIORRAFIA PERINEAL EM CÃES - RELATO DE 12 CASOS
}

\author{
Danilo Roberto Custódio Marques ${ }^{1}$ \\ Claudia Russo ${ }^{2}$ \\ José Fernando Ibañez ${ }^{3}$
}

MARQUES, D. R. C.; RUSSO, C.; IBAÑEZ, J. F. Utilização de pericárdio bovino conservado em glicerina 98\% na herniorrafia perineal em cães - relato de 12 casos. Arq. Ciênc. Vet. Zool. UNIPAR, Umuarama, v. 18, n. 3, p. 185-190, jul./set. 2015.

RESUMO: A hérnia perineal é uma afecção de alta ocorrência na clínica de pequenos animais. A doença ocorre com maior frequência em cães machos, idosos e não castrados. A etiopatogenia é multifatorial e leva à atrofia da musculatura do diafragma pélvico. Os sinais clínicos dependem muito do conteúdo herniário. O diagnóstico é realizado pelo exame físico e exames complementares. O tratamento clínico é utilizado até o animal ter condição para realização do procedimento cirúrgico que é o de eleição. Várias técnicas cirúrgicas têm sido estudadas para diminuir os índices de recidiva. A utilização de membranas biológicas pode ser usada causando sustentação do diafragma pélvico atrofiado. O pericárdio bovino preservado é muito utilizado para falhas musculares e melhorar a sustentação de tecidos. Vários métodos de preservação de membranas têm sidos utilizados, com grande destaque para glicerina 98\%. Foram avaliados 12 cães machos com hérnia perineal, na qual foi utilizado o pericárdio bovino conservado em glicerina $98 \%$ associado à técnica tradicional para a herniorrafia e orquiectomia pré-escrotal. Os cães sem raça definida foram os mais acometidos. Em cinco animais foram acometidos ambos os lados do diafragma pélvico. Somente um animal apresentou recidiva. O pericárdio bovino conservado em glicerina $98 \%$ possibilitou baixos índices de recidiva nos casos descritos.

PALAVRAS-CHAVE: Biomaterial. Canino. Cirurgia. Diafragma pélvico. Hérnia.

\section{USE OF BOVINE PERICARDIUM PRESERVED IN 98\% GLYCERINE IN PERINEAL HERNIORRHAPHY IN DOGS - 12 CASE STUDIES}

\begin{abstract}
A perineal hernia is a condition of high occurrence in small animal clinics. The disease occurs more frequently in male, elderly and unneutered dogs. The pathogenesis is multifactorial, which leads to atrophy of the muscles of the pelvic diaphragm. Clinical signs depend much of the hernia contents. The diagnosis is made by physical examination and complementary tests. Clinical treatment is used until the animal presents condition for the surgical procedure, which is the election. Several surgical techniques have been studied to reduce the relapse rates. Biological membranes can be used to support the stunted pelvic diaphragm. The preserved bovine pericardium is widely used for muscle failure and to improve tissue support. Various membrane preservation methods have been used, with emphasis to $98 \%$ glycerin. A total of 12 male dogs with perineal hernia, in which the bovine pericardium preserved in $98 \%$ glycerin associated with the traditional technique of hernia repair and pre scrotal orchiectomy were evaluated. The mongrel dogs were the most affected. In five animals, both side of the pelvic diaphragm were affected. Only one animal had recurrence. The bovine pericardium preserved in $98 \%$ glycerin allowed low recurrence rates in the cases described.
\end{abstract}

KEYWORDS: Biomaterial. Canine. Surgery. Pelvic diaphragm. Hernia.

\section{UTILIZACIÓN DE PERICARDIO BOVINO CONSERVADO EN GLICERINA 98\% EN LA REPARACIÓN DE HERNIA PERINEAL EN PERROS - RELATO DE 12 CASOS}

\begin{abstract}
RESUMEN: La hernia perineal es una afección de alta ocurrencia en clínica de animales pequeños. La enfermedad se presenta con mayor frecuencia en perros machos, de edad avanzada y no castrados. La patogénesis es multifactorial que conduce a la atrofia de los músculos del diafragma pélvico. Los signos clínicos dependen mucho del contenido de la hernia. El diagnóstico se realiza por exámenes físico y exámenes complementares. El tratamiento clínico es utilizado hasta el animal tener condiciones para realización de procedimiento quirúrgico, que es de elección. Varias técnicas quirúrgicas han sido estudiadas para disminuir las tasas de recurrencia. El uso de membranas biológicas puede ser utilizado, causando apoyo del diafragma pélvico atrofiado. El pericardio bovino conservado es ampliamente utilizado para el fallo muscular y mejorar los tejidos de soporte. Varios métodos de preservación de membranas han sido utilizados, con gran énfasis para glicerina $98 \%$. Se evaluaron 12 perros machos con hernia perineal, en los que se utilizó el pericardio bovino conservado en glicerina 98\% asociada con la técnica tradicional para reparación de la hernia perineal y orquiectomía pre escrotal. Los perros sin raza definida fueron los

DOI: https://doi.org/10.25110/arqvet.v18i3.2015.5540

${ }^{1}$ Mestrando da Universidade Federal do Paraná. Médico Veterinário Cirurgião de Tecidos Moles e Ortopedia do Hospital Veterinário Anclivepa - São Paulo. danvetmarques@gmail.com, Rua dos Democratas, 543, ap. 34, Bairro Vila Monte Alegre, Edifício Advanced Way, CEP: 04305-000.

${ }^{2}$ Professora do Qualittas Pós-Graduação, Proprietária da Clínica Convet Maringá - Cirurgia e Oncologia Veterinária. Doutoranda da Universidade Estadual de Londrina.

${ }^{3}$ Prof. de Clínica Cirurgia de pequenos animais e responsável pela Disciplina de Traumatologia e Ortopedia
\end{abstract}


más afectados. En cinco animales fueron afectados ambos los lados del diafragma pélvico. Sólo un animal había recaído. El pericardio bovino conservado en glicerina 98\% posibilitó bajas tasas de recurrencia en los casos descritos.

PALABRAS CLAVE: Biomaterial. Canino. Cirugía. Diafragma pélvico. Hernia.

\section{Introdução}

As hérnias perineais são comuns na clínica de pequenos animais e caracterizam-se pela ruptura de um ou mais músculos do diagrama pélvico (COSTA NETO et al., 2006; RIBEIRO, 2010). Acomete principalmente machos inteiros, adultos a idosos e pode ser uni ou bilateral (MENEZES et al., 2007; MORELLO et al., 2015).

A patogenia está associada aos vários fatores como a predisposição genética, devido à fraqueza dos músculos que compõem o diafragma pélvico, em especial do músculo elevador do ânus e dos músculos coccígeos. Outros fatores são alterações hormonais, doenças prostáticas e intestinais, lesões nervosas (FERREIRA; DELGADO, 2003; MORELLO et al., 2015). O diagnóstico é realizado pela palpação perineal e retal, exame radiográfico e a ecografia abdominal (ACAUI et al., 2010).

O tratamento clínico consiste em preparar o animal para o procedimento cirúrgico. Seu principal objetivo é aliviar e prevenir a constipação e disúria, evitando estrangulamento visceral e correção de fatores desencadeantes (DÓREA et al., 2002). Pode-se normalizar a defecação utilizando estimuladores de peristaltismo (cisaprida), emolientes fecais (lactulona), enemas e dietas com elevado teor de fibras. Realiza-se a cateterização vesical quando a vesícula urinária encontra-se no saco herniário, para evitar sua necrose e uremia (RIBEIRO, 2010).

Várias técnicas cirúrgicas são descritas para seu tratamento, entre elas a tradicional (RIBEIRO, 2010), transposição do obturador interno (SHAUGHNESSY; MONNET, 2015), semitendinoso (MORELLO et al., 2015) e uso de membranas biológicas como o pericárdio (ZERWES et al., 2011). As recidivas são as principais decorrências observadas na reparação desta enfermidade. A incidência de falha cirúrgica e as recidivas com o método de reparação padrão variam de 10 a 46\% (ZERWES et al., 2011).

Quando o anel herniário tem uma dimensão que torna impossível a aproximação dos tecidos sem criar uma tensão excessiva, pode-se utilizar um implante protético como as redes monofilamento de polipropileno ou polietileno, membranas biológicas como cartilagem auricular e pericárdio bovino (RUSSO et al., 2007).

As tentativas de atenuar o número de reincidentes constituem-se a preocupação preponderante nos trabalhos que envolvem essa doença, por isso a necessidade de experimentar um reforço às técnicas convencionais, podendo ser implantada uma membrana de pericárdio bovino após sua execução (RIBEIRO, 2010; ZERWES et al., 2011).

O uso de membranas biológicas para reparação de alterações anatômicas vem sendo motivo de pesquisas, pois esses materiais fornecem um arcabouço para a orientação da cicatrização e proporcionam sustentação dos tecidos (QUITZAN et al., 2003).

A glicerina a $98 \%$ é o meio mais utilizado na conservação de tecidos, destinadas às cirurgias reconstrutivas, por apresentar propriedades antissépticas, rápida ação desidratante e fixadora, mantendo a integridade celular e a tex- tura original dos tecidos, além de aumentar a resistência à tração sem alterar o grau de elasticidade, reduz a antigenicidade, possibilita a manutenção do enxerto em temperatura ambiente e tem baixo custo (GUIMARÃES et al., 2007; OLIVEIRA et a., 2009).

O pericárdio bovino conservado em glicerina $98 \%$ apresenta muitas vantagens como, fácil obtenção, conservação e aplicação, baixo custo, rápida desidratação e fixação, além de ser empregado em reparações de vários órgãos e estruturas com resultados animadores (BRENDOLAN et al., 2007).

O objetivo desse trabalho é descrever 12 casos de herniorrafia perineal com utilização do pericárdio bovino conservado em glicerina $98 \%$ em cães proporcionando baixos índices de complicações.

\section{Relato de Caso}

Foram realizadas 12 herniorrafias perineais em cães utilizando-se pericárdio bovino, durante o período de maio de 2011 a maio de 2013 no Hospital Veterinário do Centro Universitário de Maringá-PR (HV-UniCesumar). Os dados epidemiológicos com raça, idade, peso, lado acometido e conteúdo do saco herniário estão presentes na Tabela 1.

O diagnóstico baseou-se no exame físico detalhado, seguido pela palpação digital externa do aumento de volume e palpação retal. Foram realizados exames complementares como radiografia ou ecografia da região abdominal e pélvica a fim de se identificar possíveis alterações prostáticas, retroflexão da bexiga e anormalidades retais.

Para a montagem do banco de implante, o pericárdio bovino foi colhido em um abatedouro sendo irrigado em abundância com solução fisiológica de cloreto de sódio a $0,9 \%(\mathrm{NaCl} 0,9 \%)$ e colocado em frasco estéril contendo solução de glicerina a $98 \%$, previamente homogeneizada. O segmento de pericárdio permaneceu imerso para conservação e armazenamento em temperatura ambiente por no mínimo um mês antes do uso. O implante heterógeno foi removido do frasco com glicerina 10 minutos antes de sua utilização, irrigado abundantemente com $\mathrm{NaCl} 0,9 \%$ e imerso numa cuba rim estéril contendo a mesma solução, em temperatura ambiente para hidratação (Figura 1). O retalho de pericárdio bovino foi preparado confeccionando-se um segmento de dimensões suficientes para ocluir o defeito apresentado nos diferentes procedimentos cirúrgicos durante o período transoperatório. 
Tabela 1: Dados epidemiológicos com raça, idade, peso, lado acometido e conteúdo do saco herniário atendidos no HV-UniCesumar no período de maio de 2011 a maio de 2013, na qual utilizou-se o pericardio bovino conservado em glicerina 98\% para a herniorrafia.

\begin{tabular}{lcccl}
\hline \multicolumn{1}{c}{ Raça } & Idade (anos) & Peso $(\mathbf{K g})$ & Lado acometido & Conteúdo do saco herniário \\
\hline Cocker Spaniel & 6 & 13,4 & Bilateral & Bexiga+gordura retroperitoneal \\
\hline Pastor Alemão & 1 & 32,3 & Bilateral & Bexiga+gordura retroperitoneal \\
\hline Poodle & 4,5 & 4 & Bilateral & Próstata+gordura retroperitoneal \\
\hline Poodle & 12 & 5,2 & Esquerdo & Próstata \\
\hline SRD & 8 & 8,4 & Direito & Alça intestinal \\
\hline SRD & 5 & 10,5 & Bilateral & Próstata+gordura retroperitoneal \\
\hline SRD & 4 & 25,5 & Direito & Gordura retropiretoneal \\
\hline SRD & 9,5 & 17 & Esquerdo & Alça intestinal \\
\hline SRD & 10 & 15 & Bilateral & Próstata+gordura retroperitoneal \\
\hline SRD & 11,5 & 19,9 & Esquerdo & Bexiga \\
\hline SRD & 9,5 & 28,4 & Direito & Próstata \\
\hline SRD & 11 & 30,5 & Direito & Bexiga \\
\hline
\end{tabular}

Os cães foram posicionados em decúbito esternal, realizando-se sutura bolsa de tabaco no ânus com fio de náilon para realização da herniorrafia perineal. $\mathrm{O}$ conteúdo do saco herniário de todos pacientes está sumarizado na tabela 1.

Em todos os pacientes foi realizado a herniorrafia tradicional que consiste em suturas entre os músculos esfíncter externo do ânus ao ligamento sacrotuberoso e aos músculos obturador interno e coccígeo (BELLENGER, 1980), e entre os músculos esfíncter externo do ânus e obturador interno e foi associado à técnica do pericárdio bovino conservado em glicerina $98 \%$ sendo suturado no diafragma pélvico com pontos Simples Separados ou Sultan com fio de poliamida (Náilon) (Figura 2). O tecido subcutâneo e pele foram aproximados com Nylon e padrão Zig-Zag e Woff, respectivamente. Posteriormente reposicionados em decúbito dorsal e submetidos à orquiectomia por incisão pré-escrotal por meio da técnica clássica (HEDLUND, 2005).

Figura 1: Preparação do ericárdio bovino após hidratação com solução fisiológica 0,9\% para utilização na herniorrafia perineal (MARQUES, 2014).

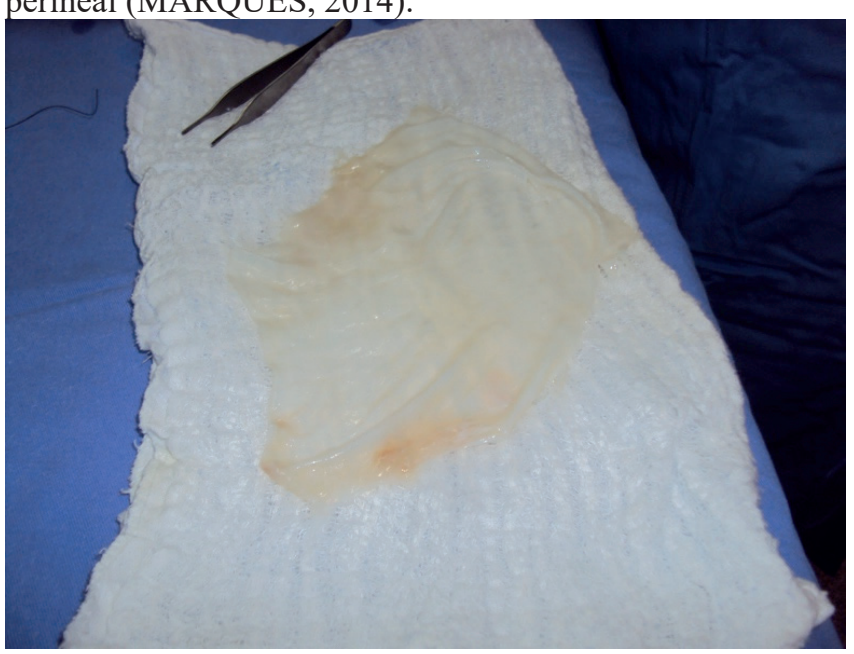

Todo o conteúdo presente no saco herniário foi posicionado em posição anatômica com o reforço no diafrag- ma pélvico do acréscimo da membrana de pericárdio bovino conservado em glicerina $98 \%$.

No período pós-operatório foram prescritos enrofloxacina $5 \mathrm{mg} / \mathrm{kg}$ por via oral a cada 12 horas durante sete dias; meloxicam $0,1 \mathrm{mg} / \mathrm{kg}$ por via oral a cada 24 horas durante cinco dias; tramadol $2 \mathrm{mg} / \mathrm{kg}$ por via oral a cada seis horas durante cinco dias; óleo mineral $3 \mathrm{~mL} / \mathrm{kg}$ por via oral a cada 12 horas durante sete dias e limpeza da ferida cirúrgica com clorexidine a $0,12 \%$ a cada seis horas

Figura 2: Trans-operatório de hérnia perineal em cão, na qual foi colocado o pericárdio bovino conservado em glicerina 98\% para dar sustentação a herniorrafia tradicional. Observa-se o pericardio bovino colocado sobre o diafragma pélvico (seta) (MARQUES, 2013).

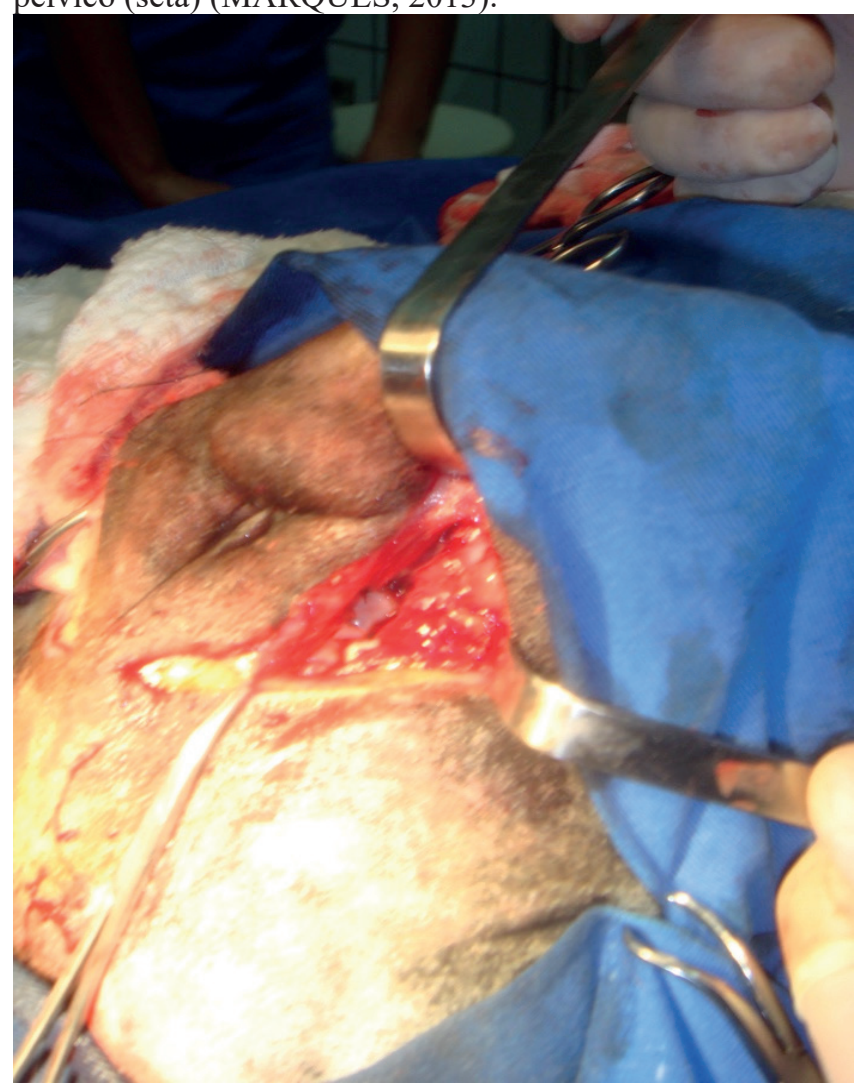




\section{Discussão}

Os animais foram avaliados 24 horas após o procedimento cirúrgico, bem como aos dez dias para retirada dos pontos. As complicações observadas no pós-operatório imediato foram seroma (um animal) e deiscência parcial de pontos (um animal). Nenhum animal apresentou reação ao implante. A recidiva foi observada somente em um animal, após 25 dias do ato cirúrgico. Esse animal foi reoperado com a mesma técnica e acompanhado até 95 dias, não apresentando mais recidiva. $\mathrm{O}$ tempo de acompanhamento pós-operatório variou de 92 até 378 dias. A recidiva é uma complicação relativamente comum, com variação entre 8 a 46\% dos casos (BELLENGER et a., 1980; HOSGOOD et al., 1995), com o uso do pericárdio bovino somente um animal apresentou recidiva $(8,33 \%)$.

As raças mais acometidas são: Boston Terrier, Boxer, Collie, Welsh Terrier, Pequinês, Dachshunds e Pastor Alemão (FEREIRA; DELGADO, 2003). Do total de animais $66,67 \%$ era sem raça definida, sendo que esse dado é difícil de ser avaliado devido ao grande atendimento de animais sem raça definida no Hospital Veterinário do UniCesumar. Os animais sem raça definida foram os mais acometidos em outros trabalhos (DELECK et al., 1992; DÓREA et al., 2002).

A média da idade e do peso dos pacientes foi de nove anos e 12,78 kg, respectivamente. Dos cães submetidos ao procedimento cirúrgico, quatro apresentaram aumento de volume na região perineal direita $(33,33 \%)$, três na esquerda $(25,01 \%)$ e cinco bilaterais $(41,66 \%)$. A hernia perineal acomete principalmente animais idosos (ANDERSON et al., 1998; DÓREA et al., 2002; SHAUGHNESSY; MONNET, 2015), concordando com dados encontrados nesse trabalho. O acometimento bilateral foi o mais observando, assim como, encontrado por Morello et al. (2015), discordando de outros trabalhos que citam o lado direito como o mais acometido (DALECK et al., 1992; DÓREA et al., 2002)

As hérnias perineais apresentam características clínicas peculiares e são mais frequentes em machos da espécie canina (MORTARI; RAHAL, 2005; ZERWES et al., 2011, MORELLO et al., 2015), dado evidenciado no presente estudo. Para admissão do diagnóstico, é importante, a história clínica, sinais clínicos, exames físicos e complementares como ultrassonografia e radiografia, para o diagnóstico de possíveis alterações antes do procedimento cirúrgico e diagnosticar qual estrutura está no saco herniário (BELLENGER; CANFIELD, 1998; DÓREA et al., 2002). Nesse caso o diagnóstico foi realizado pelo exame físico com a palpação do saco herniário e retal, além dos exames de radiografia ou ecografia para identificar o conteúdo herniário.

As hérnias perineais em cães são geralmente unilaterais $(75 \%)$, apresentando uma faixa etária de risco elevado entre os seis e os 14 anos, com uma incidência máxima entre os sete e os nove anos de idade (RIBEIRO, 2010). De fato, nesse estudo a maior ocorrência foi bilateral e os animais idosos os mais acometidos com média de idade de nove anos.

O principal conteúdo do saco herniário é a gordura retroperitonial (ACAUI et al., 2010), mas nesse estudo o conteúdo mais comum foi a bexiga e próstata. Não possível explicar essas diferenças, mas a bexiga e a próstata são conteúdos possíveis neste tipo de hérnia (DÓREA et al., 2002;
MANN; ROCHAT, 1998).

A atrofia da musculatura é um fator preponderante no aparecimento da hérnia perineal. Sendo que em muitos casos a porção caudal do músculo elevador do ânus, não é observada devido à intensa atrofia (MANN; ROCHAT, 1998; MORTARI; RAHAL, 2005) Esses dados interagem com o que foi observado nesse estudo, em que foram registrados graus variados de atrofia da musculatura do diafragma pélvico em todos os animais. O músculo elevador do ânus foi o músculo mais acometido nesse trabalho, assim, como encontrado por Zerwes e colaboradores (2011).

A glicerina a $98 \%$ apresenta várias vantagens como conservante de membranas biológicas (MOTA et al., 2002; BAUCIA et al., 2006; GUIMARÃES et al., 2007; VULCANI et al., 2008; OLIVEIRA et al., 2009; VULCANI et al., 2013), por isso foi o meio de preservação utilizado nesse estudo, sendo que não foram observados infecção e reação ao implante no período pós-operatório imediato e a longo prazo. A glicerina $98 \%$ foi eficiente na conservação das características morfológicas do pericárdio bovino e não permitiu o crescimento de micro-organismos como fungos e bactérias (BARIANI JÚNIOR et al., 2014).

A utilização de membrana nos cães pode ter sido o fator preponderante para a ausência de recidiva, podendo-se sugerir que o uso de membrana de pericárdio bovino em pacientes com graus variados de atrofia constitui-se em alternativa na correção cirúrgica de hérnias perineais em cães (ZERWES et al., 2011). Outros trabalhos utilizaram membranas biológicas para tratamento de hérnia perineal com resultados satisfatórios (DÓREA et a., 2002; RUSSO et al., 2007; RIBEIRO, 2010; ZERWES et al., 2011).

A castração dos machos é recomendada concomitante com a herniorrafia por reduzir os casos de insucesso por diminuir a testosterona circulante e o volume da próstata. Cães inteiros apresentam uma taxa de recorrência 2,7 vezes superior à dos cães castrados (MORTARI; RAHAL, 2005), sendo que receptores para hormônios androgênicos estão presentes na musculatura do diafragma pélvico, e o aumento de di-hidrotestosterona circulante possa levar a atrofia deste (ACAUI, 2001). Embora essa indicação de tratamento seja comprovada, é possível verificar cães machos operados de hérnia perineal, não castrados (BONGARTZ et al.; 2005). Os animais desse estudo foram orquiectomizados, pois esse procedimento diminui o índice de recidiva pós-operatório (ANDERSON et al., 1998; HOSGOOD et al., 1995),

Em um trabalho realizado por D'Assis e colaboradores (2010) foi observado hipertrofia prostática em cães com hérnia perineal, justificando o emprego da orquiectomia associado a herniorrafia perineal. Muitos dos animais desse trabalho eram idosos, aumentando a incidência de doenças prostáticas. Além disso, em quatro casos a próstata era o conteúdo do saco herniário.

A diferença dessa técnica de reforço com as demais publicadas sobre o uso de membranas na correção de hérnia perineal é a forma de utilização, no trabalho em questão o material foi ancorado nas bordas da musculatura para correção do defeito do diafragma pélvico e foi usado fio não absorvível. O fio absorvível não possibilita sustentação suficiente para a cicatrização (ANDERSON et al., 1998; DALECK et al., 1992), como encontrado com os fios não absorvíveis, em que ocorre uma resposta inflamatória prolongada determi- 
nando maior grau de fibrose e, portanto, maior resistência (ZERWES et al., 2011). No presente estudo foram utilizados fios de sutura não absorvíveis monofilamentoso (náilon), o que proporcionou maior resistência no local de sutura. $\mathrm{O}$ fio de náilon proporciona uma resistência mais prolongada e firmeza à sutura até a completa cicatrização da herniorrafia perineal (DÓREA et al., 2002; RAISER et al., 1992).

A ocorrência de recidiva foi de 8,33\% (um animal), sendo esse valor abaixo do encontrado em outros trabalhos (BURROWS; HARVEY, 1973; ZERWES et al., 2011). Nesse estudo o tempo de acompanhamento médio pós-cirúrgico foi de 232 dias, mostrando que as recidivas não ocorram mesmo após longo período do ato cirúrgico. Em um estudo retrospectivo de 34 casos de hérnia perineal, tratou-se com uso técnica da transposição do obturador interno e em três animais desenvolveu-se a hérnia no lado contra-lateral entre 35 a 95 dias de pós-operatório (SHAUGHNESSY; MONNET, 2015).

A infecção da ferida, deiscência de pele, incontinência fecal, tenesmo, lesão do nervo isquiático e formação de abscesso são problemas prevalentes em hérnias perineais de cães, com taxa de ocorrência que variam de 6,4 a $26 \%$ (BELLENGER; CANFIELD, 1998). A taxa de complicações observadas nesse estudo foi de dois animais $(16,67 \%)$, sendo que um animal apresentou deiscência parcial da sutura e outro de seroma no local da incisão.

Uma importante vantagem da utilização do pericárdio bovino conservado em glicerina $98 \%$ comparado com as malhas sintéticas é o seu baixo custo e sua manipulação.

\section{Conclusão}

O pericárdio bovino preservado em glicerina a $98 \%$ constitui-se um reforço adequado na reparação de hérnia perineal quando associado às técnicas tradicionais. Sua principal indicação é em casos de atrofia severa da musculatura do diafragma pélvico, diminuindo o número de recidivas.

\section{Referências}

ACAUI, A. Avaliação do tratamento da hérnia perineal bilateral no cão por acesso dorsal ao ânus em tempo cirúrgico único. 2001. 53 f. Tese (Mestrado em Cirurgia)

- Faculdade de Medicina Veterinária e Zootecnia, Universidade de São Paulo, São Paulo, 2001.

ACAUI, A. et al. Avaliação do tratamento da hérnia perineal bilateral no cão por acesso dorsal ao ânus. Brazilian Journal of Veterinary Research and Animal Science, v. 47, n. 6, p. 439-446, 2010.

ANDERSON, M. A.; CONSTANTINESCU, G. M.; MANN, F. A. Perineal hernia repair in the dog. In: BOJRAB, M. J. Current Techniques in Small Animal Sugery. 4. ed. Baltimore, Williams \& Wilkins, 1998. p. $555-564$

BAUCIA, J. A. et al. Tratamento anticalcificantes do pericárdio bovino fixado com glutaraldeído: comparação e avaliação de possíveis efeitos sinérgicos. Brazilian Journal Cardiovascular Surgery, v. 21, n. 2, p. 180-187, 2006.
BELLENGER, C. R. Perineal hernia in dogs. Australian Veterinary Journal, v. 56, n. 9, p. 434-438, 1980.

BELLENGER, C. R.; CANFIELD, R.B. Hérnia perineal. In: SLATTER, D. Manual de cirurgia de pequenos animais. 1ed. São Paulo: Manole, 1998, p.578-590.

BONGARTZ, A. et al. Use of autogenous fascia lata graft for perineal herniorrhaphy in dogs. Veterinary Surgery, v. 34, n. 4, p. 405-503, 2005.

COSTA NETO, J. M. et al. Tratamento cirúrgico para correção de hérnia perineal em cão com saculação retal coexistente. Revista Brasileira Saúde Produção Animal, v. 7, n. 1, p. 7-19, 2006.

DALECK.C. R. et al. Reparação de hérnia perineal, em cães, com peritônio bovino conservado em glicerina. Ciência Rural, v. 22, n. 2, p. 179-83, 1992.

D’ASSIS, M.J.M.H.; COSTA NETO, J.M.; ESTRELALIMA, A.S.; FILHO, E.F.M.; TORÍBIO, J.M.M.; TEIXEIRA, R.G. Colopexia e deferentopexia associadas à omentopexia no tratamento da hérnia perineal em cães: um estudo de trinta casos. Ciência Rural, v.40, n.2, p.371-377, fev, 2010

DÓREA, H. C.; SELMI, A. L.; DALECK, C. R. Herniorrafia perineal em cães - estudo retrospectivo de 55 casos. Ars Veterinária, v. 18, n. 1, p. 20-24, 2002.

FERREIRA, F.; DELGADO, E. Hérnias perineais nos pequenos animais. Revista Portuguesa de Ciências Veterinárias, v. 545, n. 45, p. 3-9, 2003.

GUIMARÃES, G. C. et al. Avaliação histiológica de membranas biológicas bovinas conservadas em glicerina e a fresco. Bioscience Journal, v. 23, n. 3, p. 120-127, 2007.

HEDLUND, C. S. Cirurgia do trato Reprodutivo Masculino. In: FOSSUM, T. W. Cirurgia de Pequenos Animais. 2. ed. São Paulo: Roca, 2005, p.648-672.

HOSGOOD, G. et al. Perineal herniorrhaphy, perioperative data from 100 dogs. Journal of the American Animal Hospital Association, v. 31, n. 4, p. 331-342, 1995.

BARIANI JÚNIOR, A. F. et al. Análise morfológica e microbiológica do pericárdio bovino conservado em açúcar, glicerina, mel e sal. Veterinária Notícia, v. 20, n. 2, p.1524, 2014.

MANN, F. A.; ROCHAT, M. C. Sciatic perineal hernia in two dogs. Journal of Small Animal Practice, v. 39, n. 5, p. 240-243, 1998.

MENESES, L. B. et al. Hérnia perineal associada à colagenopatia em uma cadela. Acta Scientiae Veterinariae, v. 35, n. 3, p. 377-379, 2007.

MORELLO, E. et al. Modified semitendinosus muscle 
transposition to repair ventral perineal hernia in 14 dogs.

Journal of Small Animal Practice, v. 56, n. 6, p. 370-376, 2015.

MORTARI, A. C.; RAHAL, S. C. Hérnia Perineal. Ciência

Rural, v. 35, n. 5, p. 1220-1228, 2005.

MOTA, F. C. D. et al. Análise ultra-estrutural da túnica muscular do intestino delgado de cães preservado em diferentes meios. Brazilian Journal of Veterinary Research and Animal Science, v. 39, n. 1/6, p. 13-17, 2002.

OLIVEIRA, L. L. et al. Métodos de preservação de membranas biológicas para uso cirúrgico. Jornal Brasileiro de Ciência Animal, v. 2, n. 3, p. 175-188, 2009.

QUITZAN, J. G. et al. Comparação entre o pericárdio bovino preservado em glicerina e malha de poliéster no reparo de falhas da parede abdominal em ratos. Acta Cirúrgica Brasileira, v. 18, n. 4, p. 297-301, 2003.

RAISER A. G. Herniorrafia perineal em cães, análise de 35 casos. Brazilian Journal of Veterinary Research and Animal Science, v. 31, n. 34, p.252-60, 1994.

RIBEIRO, J. C. Hérnia perineal em cães: Avaliação e resolução cirúrgica - artigo de revisão. Revista Lusófona de Ciência e Medicina Veterinária, v. 3, p. 26-35, 2010.

RUSSO, C. et al. Herniorrafia Perineal: Análise de três técnicas cirúrgicas. In: CONGRESSO BRASILEIRO DA ANCLIVEPA, 18., 2007, Florianópolis. Anais... Florianópolis:ANCLIVEPA, 2007.

SHAUGHNESSY, M.; MONNET, E. Internal obturator muscle transposition for treatment of perineal hernia in dog: 34 cases (1998-2012). Journal of the American Veterinary Medical Association, v. 246, n. 3, p. 321-326, 2015.

VULCANI, V. A. S. et al. Implantação de biomembrana de colágeno tratada em solução alcalina ou conservado em glicerina a $98 \%$ na parede abdominal de eqüinos. Ciência Rural, v. 43, n. 8, p. 1422-1428, 2013.

VULCANI, V. A. S.; MACORIS, D. G.; PLEPIS, A. M. G. Membranas biológicas homólogas preservadas em solução alcalina seguida de liofilização, glicerina a $98 \%$ e por liofilização para implantação em eqüinos. Ciência Rural, v. 38, n. 5, p. 1329-1334, 2008.

ZERWES, M. B. C. et al. Avaliação do tratamento cirúrgico da hérnia perineal em cães com o reforço de membrana de pericárdio eqüino preservado em glicerina a $98 \%$. Brazilian Journal of Veterinary Research and Animal Science, v. 48 , n. 3 , p. $220-227,2011$. 